\title{
Review of "Definition"
}

Charles Tapley Hoyt

I like the idea of a meta-definition. I would agree with the authors on how they state this. 